\title{
Exemption from Health Care Fees Influences Indications of Caesarean Section in a Urban Health District Hospital in Benin
}

\author{
Sossa Jérôme $C^{1, *}$, Sopoh $\mathbf{G E}^{2}$, Ogoudjobi $\mathbf{O M}^{3}$, Issoufou Namassa $\mathbf{F}^{4}$, Jacques Saizonou ${ }^{4}$, Aguemon $\mathbf{B}^{5}$, \\ Alphonse Kpozehouen ${ }^{6}$, Mongbo $V^{3}$, Azandjemè $C^{1}$, Aguey $V^{1}$, Ouendo $\mathbf{E M}^{3}$, Ouédraogo $\mathbf{T L}^{5}$ \\ ${ }^{1}$ Department of Health Promotion, Regional Institute of Public Health (IRSP), University of Abomey-Calavi, Benin \\ ${ }^{2}$ Department of Health and Environment, Regional Institute of Public Health (IRSP), University of Abomey-Calavi, Benin \\ ${ }^{3}$ University Hospital of Porto-Novo, Benin \\ ${ }^{4}$ Department of Health Policies Systems, Regional Institute of Public Health (IRSP), University of Abomey-Calavi, Benin \\ ${ }^{5}$ Department of Public Health, Faculty of Health Sciences of Cotonou, University of Abomey-Calavi, Benin \\ ${ }^{6}$ Department of Epidemiology and Biostatistics, Regional Institute of Public Health (IRSP), University of Abomey-Calavi, Benin
}

Copyright $\bigcirc 2017$ by authors, all rights reserved. Authors agree that this article remains permanently open access under the terms of the Creative Commons Attribution License 4.0 International License

\begin{abstract}
Rising caesarean birth rates in recent decades are an issue of public health. Potential harms for mothers and newborns are associated with caesarean delivery. Determinants of caesarean birth rates in Benin are unknown. The objective was to assess changes in caesarean rate and compare its indications before and during the implementation of policy of caesarian section fee exemption (PCSFE) in an urban district hospital in Cotonou, Benin. This cross-sectional study conducted at Suru Léré hospital, Cotonou, in 2014. Data on caesarean section were collected from completed medical records of 2104 women who underwent caesarean section before and during the implementation of the PCSFE. Caesarean rates by quarter varied between $17 \%$ and $26 \%(\mathrm{p}=0,133)$ before the PCSFE while the rate increased significantly from $28 \%$ to $48 \%$ $(p<0,001)$ during the implementation PCSFE. During the period of implementation of PCSFE, frequencies of "placenta prævia" $(p=0.022)$ and excessive uterine height ( $p$ $<0.001)$ were significantly higher while frequencies of "uterine pre-rupture syndromes" $(\mathrm{p}=0.017)$ and generally contracted pelvis $(\mathrm{P}=0.013)$ decreased compared to period prior the PCSFE. Caesarean section rate increased during the implementation PCSFE and some caesarean section indications increased during the PCSFE. Further prospective studies are needed to follow the evolution of indications of caesarean section to inform preventives measures in urban district hospital Suru Léré Cotonou.
\end{abstract}

Keywords Fee Exemption Policy, Caesarean Section, Indications, Benin

\section{Introduction}

Maternal and neonatal mortality is a public health problem in developing countries. Caesarean section contributes to reduce complications associated with childbirth [1]. Taking into account the model of the three delays affecting care seeking, referral and providing appropriate emergency obstetric care in a timely manner [2], Benin instituted free caesarean section by in 2008 with the aim of reducing maternal mortality. This policy of free caesarean section care contributes to an increase in the rate of caesarean section from $3.7 \%$ in 2009 to $6.4 \%$ in 2012 according to study in four health districts [3]. Studies conducted in 2012 and 2013 have reported increased caesarean section rates in several health districts in rural and semi-urban areas from one to two points $[4,5]$.

Caesarean section, however, is associated with maternal and fetal complications [6-8] such as surgical wound infections, thromboembolic complications, and neonatal respiratory distress [9]. These complications could threat mother and baby health [10]. Even when a good caesarean section is performed, recovery after surgery usually takes longer than normal vaginal delivery [11].

In a recent study of 32443 caesarean sections in a university hospital in the United States of America between 2003 and 2009, Barber et al. [12] found an increase in subjective caesarean indications (fetal suffering and stationary dilation) compared with objective indications (abnormal presentation, circular umbilical cord, placenta prævia). In a recent systematic review, Mylonas et al. [1] reported that an increase in the number of elective caesarean sections performed is considered to be a major cause of the rise in caesarean section rates. The indications for caesarean 
section have changed in many countries, including today's social factors such as anxiety about and the mother's wish to have a caesarean section in the absence of any medical indication.

The objective of the study was to assess changes in caesarean section rate and compare its indications before and during the implementation of free caesarean section fee exemption (PCSFE) in an urban district hospital in Cotonou, Benin.

\section{Materials and Methods}

\subsection{Setting}

The study was carried out in Suru Léré area hospital in Cotonou, Benin in 2014. It is a public non-profit health district hospital in the main urban city in Benin. The inhabitant of the health district was estimated at 297099 including 11884 children and 87555 women of child-bearing age. The average density was 11884 inhabitants $/ \mathrm{km}^{2}$. Suru Léré health district covered 45 urban outskirts, six public care facilities including one health district hospital and 132 private health centers [14]. The medical and surgical services in the hospital were pediatrics, medicine, surgery, gynecology obstetrics, radiology, stomatology and otorhinolaryngology. The obstetrics and gynecology department had two surgery units and the staff consisted of five gynecologists, four nurses, 21 midwives.

\subsection{Study Design and Material}

This was a cross-sectional study. The study material consisted of the medical records of women who underwent caesarean in Suru Léré health district hospital before and during the implementation of the PCSFE, whether admitted directly or referred from other health facilities. The study was carried out from $2^{\text {nd }}$ to $30^{\text {th }}$ June 2014.

\subsection{Selection of Medical Records}

Study material was medical report of pregnant women who experienced caesarean section. Out of eligible medical reports (medical reports belonging the study period), only ones with complete required data were selected. All the medical report for women who underwent cesarean section from 2008 (15 months before PCSFE) to 2011 (three years of implementation of the PCSFE) with complete required data on socio-demographic factors and indication of caesarean section were selected.

\subsection{Variables of the Study}

The dependent variable was the indications for caesarean sections. The independent variable was the period when the caesarean section was performed: before the implementation of the PCSFE or during the implementation of the PCSFE.

\subsection{Data Collection}

Data were collected through a documentary review of the medical records of patients. Data collectors extracted information regarding the variables from these documents.Data were collected in the health district hospital from $2^{\text {nd }}$ to $30^{\text {th }}$ June 2014 by a student of Master in Public Health, assisted by a nurse.

\subsection{Ethical Considerations}

The objectives of the study were explained to the managers of the Suru Léré hospital and their agreement was obtained before starting and collecting data. Confidentiality and anonymity were respected when processing medical records and disseminating the results.

\subsection{Data Analysis}

Data analysis was performed by SPSS software, version 20.0 (SPSS Inc., Chicago, IL). Relative frequencies were calculated and the averages estimated with their standard deviations. The Pearson chi-square statistical test for trend was used to assess trend of caesarean section rates before and during the PCSFE. The independent " $\mathrm{t}$ " test was used for mean comparison. Pearson chi-square statistical test was used to compare proportions of indications of caesarean section rates before and during the implementation of PCSFE. The significance level was set at $\mathrm{p}<0.05$.

\section{Results}

Of the 2,450 caesarean sections performed from 2008 to 2011 at the Suru Léré district hospital, only 2104 (86\%) medical records contained the information required for the study (socio-demographic data and the indication of caesarean section). Of the 2104 caesarean sections taken into account, 411 were related to the caesarean sections performed before the PCSFE and 1693 during the PCSFE.

\subsection{Characteristics of Women}

The average ages (years) of women who underwent caesarean were $27.81 \pm 5.9$ and $26.81 \pm 5.7$ before and during the PCSFE respectively $(\mathrm{p}<0.001)$. Among the women who experienced caesarean section before PCSFE, $88.1 \%$ were referred versus $49.2 \%$ during the implementation of the PCSFE, $(\mathrm{p}<0.001)$. Prior to the PCSFE, $5.9 \%$ of women who underwent caesarean section utilized four times antenatal care services, compared with $15.9 \%$ during the implementation of the PCSFE ( $p=0.027)$. Before the PCSFE, $5.0 \%$ of women who experienced more than three pregnancies underwent caesarean section, compared with $13.6 \%$ during the implementation of the PCSFE $(p=0.044)$. Concerning number of deliveries, primiparous women accounted for $58.4 \%$ before the PCSFE and $57.0 \%$ during the PCSFE. 


\subsection{Evolution of Cesarean Section Rates}

Figure 1 illustrates the evolution of the quarterly rates of caesarean section prior and during the implementation of the PCSFE based on Chi square for trend test. The rate of caesarean section gradually increased from $28 \%$ to $48 \%$ $(p<0.001)$ during the PCSFE. No significant change was found in the rate of caesarean section which ranged from $17 \%$ and $26 \%(\mathrm{p}=0.133)$ during the period before the PCSF. Most of caesarean sections, $82.2 \%$ and $80.8 \%$ were realized in emergency context during period before and during the implementation of the PCSFE, respectively.

\subsection{Indications of Caesarean Sections}

Table 1 summarizes the comparison of proportion of indications before and during the implementation of the PCSFE. The main indications for caesarean sections during the period before the PCSFE were: generally contracted pelvis $(20.9 \%)$, fetal distress $(18.5 \%)$, eclampsia (15.3\%) and the foeto-pelvic disproportion (10.7\%). The main indications for caesarean sections during the period implementation of PCSFE were: fetal distress (19.8\%), eclampsia $(17.0 \%)$, generally contracted pelvis $(15.5 \%)$ and the foeto-pelvic disproportion (9.0\%). During the period of implementation of PCSFE, frequencies of "placenta prævia" $(p=0.022)$ and excessive uterine height $(p<0.001)$ were significantly higher while frequencies of "uterine pre-rupture syndromes" $(\mathrm{p}=0.017)$ and generally contracted pelvis $(\mathrm{P}=0.013)$ were lower compared to period prior the PCSFE.

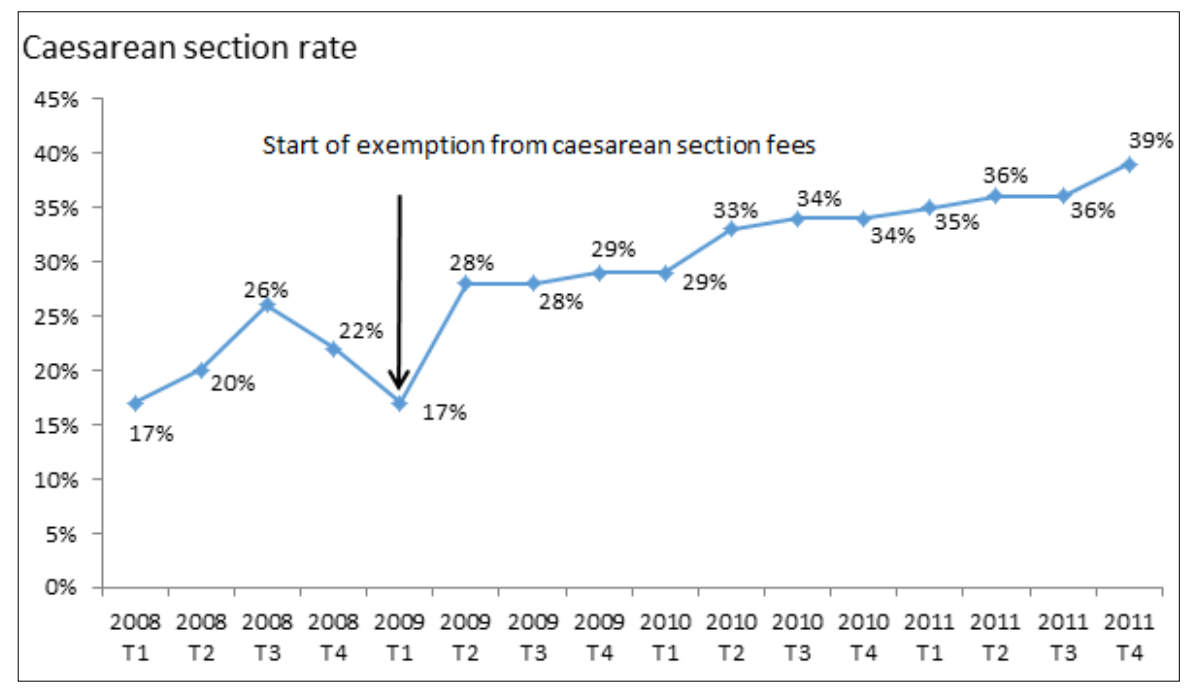

Figure 1. Changes in caesarean section rate before and during the exemption from heath care fees, Hospital Suru Léré (2104), Cotonou, Benin, 2014

Table 1. Indications of caesarean section rate before and during the exemption from heath care fees, $(\mathrm{n}=2104)$, Hospital Suru Léré, Cotonou, Benin, 2014

\begin{tabular}{|c|c|c|c|}
\hline \multirow{2}{*}{ Indications } & \multicolumn{3}{|c|}{ Context } \\
\cline { 2 - 4 } & $\begin{array}{c}\text { Before the policy of health } \\
\text { care fee exemption N (\%) }\end{array}$ & $\begin{array}{c}\text { During the policy of health } \\
\text { care fee exemption N (\%) }\end{array}$ & p \\
\hline Generally contracted pelvis & $86(20,9)$ & $335(19,8)$ & $0,013)$ \\
\hline Fetal distress & $76(18,5)$ & $152(9,0)$ & 0,529 \\
\hline Feto-pelvic disproportion & $44(10,7)$ & $287(17,0)$ & 0,328 \\
\hline Eclampsia & $63(15,3)$ & $146(8,6)$ & 0,497 \\
\hline Abnormal presentations & $30(7,3)$ & $102(6,0)$ & 0,436 \\
\hline Macrosomia & $23(5,6)$ & $71(4,2)$ & 0,364 \\
\hline Premature rupture of membranes & $21(5,1)$ & $38(2,2)$ & $\mathbf{0 , 0 1 7}$ \\
\hline Uterine pre-rupture & $19(4,6)$ & $83(4,9)$ & 0,051 \\
\hline Arrest of dilatation & $9(2,2)$ & $54(3,2)$ & $\mathbf{0 , 0 2 2}$ \\
\hline Placenta praevia & $8(1,9)$ & $29(1,7)$ & 0,999 \\
\hline Retro-placental hematoma & $4(1,0)$ & $86(5,1)$ & $<\mathbf{0 , 0 0 1}$ \\
\hline Excessive uterine height & $4(1,0)$ & $47(2,8)$ & $\mathbf{1 6 9 3}$ \\
\hline Other dystocia & $24(5,8)$ & $\mathbf{4 1 1}$ & $<, 001$ \\
\hline Total & & & \\
\hline
\end{tabular}




\section{Discussion}

This study examined the evolution of the caesarean section rate and its indications in periods before and during the implementation PCSFE in urban heath district hospital in Cotonou, Benin. Quarterly caesarean rates were statistically stable during the period prior the PCSFE but increased significantly during the period of implementation of the PCSFE. Frequencies of some indications of cesarean section varied significantly across the two periods.

\subsection{Changes in Caesarean Section Rates}

The period of implementation of PCSFE was associated with an increase of the caesarean section rate in the district hospital. This observation is similar to those reported by Ouédraogo et al. [15] in Ouidah health district hospital in Benin where they reported that free caesarean section contributed to the increase of caesarean section rate from $2.38 \%$ in 2009 to $3.48 \%$ in 2012 . Similarly, in a study on the impact of free caesarean section at the Kangaba circle health center in Mali, Ballo [16] observed that caesarean section rate increased from $15 \%$ to $22.4 \%$. Diallo [17] observed in the referral health center of Keniéba in Mali that the rate of caesarean section increased from $2.76 \%$ before the PCSFE to $7.25 \%$ during the PCSFE. At Yale-New Haven University Hospital in the USA, the caesarean rate increased from $26 \%$ to $36.5 \%$ between 2003 and 2009 [12]. Since families no longer have to pay for caesarean sections and based on the model of the three delays affecting the use of care in a timely manner [2], the PCSFE can contributes to improvement of maternal care services utilization.

This economic accessibility to health care and "too early sex activities" could explain the finding that women that underwent cesarean section became younger. However, vigilance needs to be observed as Mbaye et al., [18] reported in Senegal that the spirit of "doing more, to earn more" prevailed in hospitals where maternity is considered a dairy cow. Caesarean section is associated with short- and long-term risks that may persist for several years after delivery and affect child and women's health and next pregnancies [19]. More ever, Ravit [20] reported that despite exemption of cesarean section fees, $91 \%$ of women continue to pay for their treatment for direct-paying care such as blood transfusion, antibiotic therapy, and Antihypertensive drugs.

The decrease in the first quarter in 2009 (before PCSFE) compared to the high increase in second quarter in 2009 (beginning of PCSFE), may be due to saw-tooth trend of caesarean section rate before the PCSFE confirmed by other study in northern Benin setting [4]. If data tracking was, per example, five years before PCSFE, succession of decrease and increase could be observed, knowing that the PCSFE explains the high increase in in second quarter in 2009.

\subsection{Indication of Caesarean Sections}

The frequencies of "placenta prævia" and excessive uterine height were significantly higher during the implementation of the PCSFE. In a study in Mali, Diallo [17] reported that mechanical dystocia was the most frequent caesarean section indication with $18.81 \%$ before the implementation of the PCSFE and 56.43\% during the implementation of the PCSFE $(p<0.05)$. The main indications for Caesarean section at the Douala General Hospital in 2012 were: fetal distress $(17.00 \%)$, scarred uterus $(12.56 \%)$ and seat presentation (11.49\%) [21]. In the present study, the increase in the frequency of placenta preaviea and excessive uterine height may be explained by improved access to maternal care assuming that these conditions were previously managed with failure at home or at first line health care facilities. According to the results of the study conducted Barber et al. [12], which included 32,443 live births at the university hospital between 2003 and 2009, there were more subjective indications (fetal suffering and stationary dilatation) that largely contribute to the increase in caesarean section than the objective indications such as abnormal presentation (abnormal presentation and maternal affections). Caesarean sections have been reported at the request of mothers with no clinical indication $[22,23]$. We have not explored this situation in the study.

Generally contracted pelvis and pre-rupture syndromes decreased between the two periods. The decrease in pre-rupture syndromes can be explained by timely access to hospital and diligent care at the hospital [2] due to the exemption from fees. Early care can obviously reduce obstetric complications related to delay in referrals to care.

The frequency of fetal distress were statistically stable across the two contexts of payment mode in contrast of findings in Mali (2008) where authors reported a decrease in the frequency of fetal distress and uterine pre-ruptures [16] as well as foeto-pelvic disproportions [24] during the implementation of the PCSFE. According to Barber et al. [12], fetal distress is a subjective indication. The non-expected stability of the frequency of fetal distress can be explained by this subjectivity associated with this indication.

The limitations of this study concern the geographic scope limited to a health district hospital. The sampling techniques were not at random. This may include some possible selection biases. Further, data were collected through only complete medical records. Then differences in cesarean section could arise from differences in group's socio-demographic characteristics and not from PCSFE that are not always well filled in resource-limited countries. The two periods considered haven't the same duration.

\section{Conclusions}

Caesarean section rate increased during the implementation PCSFE and some caesarean section indications change across the two contexts. Among indications of cesarean section, frequencies of "placenta 
prævia" and excessive uterine height increased while "pre-rupture uterine syndromes" and "generally constricted pelvis" decreased. Further prospective studies are needed to follow the evolution of indications of cesarean section to inform preventives measures in urban district hospital Suru Léré Cotonou.

Any comments and suggestions are welcomed so that we can constantly improve this template to satisfy all authors' research needs.

\section{Conflict of Interest}

Authors declare no conflict of interest.

\section{Acknowledgements}

We are very grateful to managers of Suru Léré health district.

\section{Authors' Contribution}

SJC, SGE, and INF wrote the proposal and supervised data collection. SJC, SGE and OOM did the analysis. INF and SJC wrote the draft of the report. All authors contributed to final version of the manuscript.

\section{REFERENCES}

[1] Mylonas I, Friese K. Indications for and Risks of Elective Cesarean Section. Dtsch Arztebl Int 2015; 112: 489-95.

[2] Thaddeus S, Maine D. Too far to walk: maternal mortality in context. Soc Sci Med 1994; 38: 1091-110.

[3] FEMHealth. Evaluation de trois années de mise en œuvre de la politique de gratuité de la césarienne dans cinq zones sanitaires du Bénin Cotonou, 2014.

[4] Ministère de la santé du Bénin. Evaluation de la mise en œuvre de la gratuité de la césarienne dans le département de la Donga Cotonou, 2012.

[5] Ouedraogo TL, Kpozehouen A, Glegle-Hessou Y, Makoutode M, Saizonou J, Tchama-Bouraima M. [Evaluation of free cesarean sections in Benin]. Sante Publique 2014; 25: 507-15.

[6] Ashtiani N, Hagmolen of ten Have W, Vreede WT, Vogt WP, van Elburg RM. [Respiratory complications in early elective caesarean section]. Ned Tijdschr Geneeskd 2009; 153:A57.

[7] Maric T, Tomic V, Darko K. [Puerperal complications in nulliparous women delivered by section caesarean: pair study]. Med Arh 2006; 60: 246-50.

[8] McDonnell NJ, Paech MJ, Clavisi OM, Scott KL. Difficult and failed intubation in obstetric anaesthesia: an observational study of airway management and complications associated with general anaesthesia for caesarean section. Int J Obstet Anesth 2008; 17: 292-7.

[9] Bulow-Lehnsby AL, Gronbeck L, Krebs L, Langhoff-Roos J. [Complications of elective Caesarean section performed by a special section team]. Ugeskr Laeger 2006; 168: 4088-90.

[10] Jonsdottir G, Bjarnadottir RI, Geirsson RT, Smarason A. [No correlation between rates of caesarean section and perinatal mortality in Iceland]. Laeknabladid 2006; 92:191-5.

[11] Hounton SH, Newlands D, Meda N, De Brouwere V. A cost-effectiveness study of caesarean-section deliveries by clinical officers, general practitioners and obstetricians in Burkina Faso. Hum Resour Health 2009; 7:34.

[12] Barber EL, Lundsberg LS, Belanger K, Pettker CM, Funai EF, Illuzzi JL. Indications contributing to the increasing cesarean delivery rate. Obstet Gynecol 2011; 118: 29-38.

[13] Stjernholm YV, Petersson K, Eneroth E. Changed indications for cesarean sections. Acta Obstet Gynecol Scand 2009;89: 49-53.

[14] Mairie de Cotonou. Plan de Développement Communal de la Ville de Cotonou (PDC Cotonou). Direction de la Prospective et du Développement Municipal. Miarie de Cotonou Cotonou: Miarie de Cotonou, 2008.

[15] Ouedraogo TL, Kpozehouen A, Gléglé-Hessou2 Y, Makoutodé2 M, Saizonou2 J, Tchama-Bouraima $M$. Evaluation de la mise en œuvre de la gratuité de la césarienne au Bénin. Santé Publique 2013;25:507-15.

[16] Ballo I. Impact de la gratuité de la césarienne au centre de santé de référence du cercle de Kangaba [Thèse]. Bamako: Université de Bamako; 2008.

[17] Diallo A. Etude de la césarienne avant et pendant la gratuité au centre de santé de Kéniéba au Mali [These]. Bamako: Université de Bamako; 2010.

[18] Mbaye EM, Dumont A, V. R, Briand V. «En faire plus, pour gagner plus »: la pratique de la césarienne dans trois contextes d'exemption des paiements au Sénégal

[19] Mbaye EM, Dumont A, Ridde V, Briand V. [Doing more to earn more: cesarean sections based on three cases of exemption from payment in Senegal].Santé Publique 2001 2011;3: 207-19.

[20] World Health Organization. WHO Statement on Caesarean Section Rates. Available at: $<$ http://apps.who.int/iris/bitstream/10665/161442/1/WHO _RHR_15.02_eng.pdf $>$ Accessed 15/08 2016.

[21] Ravit R, Philibert P, Tourigny C, Traore M, Coulibaly A, Dumont A, Fournier P. The Hidden Costs of a Free Caesarean Section Policy in West Africa (Kayes Region, Mali). Matern Child Health J 2015; 19: 1734-43.

[22] Nguefack C, Priso E, Njamen T, Bilkissou M, Ekane G, Kamgaing J, Obinchemti T, Foumane P. L'accouchement par césarienne à l'Hôpital Général de Douala : incidence, indications et complications. Revue de Médecine et de Pharmacie 2012;2:205-12.

[23] Penn Z. Indications for caesarean section. Best Pract Res Clin Obstet Gynaecol 2001; 15: 1-15.

[24] Al-Kadri H, Al-Anazi S, Tamim H. Increased cesarean section rate in Central Saudi Arabia: a change in practice or different maternal characteristics. International Journal of Women's Health 2015; 7 685-92.

[25] Traoré I. Impact de la gratuité de la cesarienne au centre de santé de référence du cercle de Baroueli [Thèse]. Bamako: Université de Bamako; 2008 